\title{
Parameter Estimation of Neutral Grounding Reactor for a Single Line to Ground Fault for Transformer
}

\author{
Snehal Pimpalkar¹, Mr. Mahesh Mankar² \\ ${ }^{1}$ M.Tech Student, ${ }^{2}$ Company Employee \\ ${ }^{1}$ Shri Ramdeobaba College of Engineering and Management, Nagpur, Maharashtra, India \\ 2Paramount Conductors Ltd, Nagpur, Maharashtra, India
}

\begin{abstract}
How to cite this paper Snehal Pimpalkar / Mr. Mahesh Mankar "Parameter Estimation of Neutral Grounding Reactor for a Single Line to Ground Fault for Transformer" Published in International Journal of Trend in Scientific Research and Development (ijtsrd), ISSN: 24566470, Volume-3 I Issue-3, April 2019, pp.784-786, URL: https://www.ijtsrd.co $\mathrm{m} /$ papers/ijtsrd2303 o.pdf

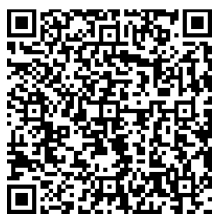
IITSRD23030

Copyright (C) 2019 by author(s) and International Journal of Trend in Scientific Research and Development Journal. This is an Open Access article distributed under the terms of the Creative Commons Attribution License (CC BY 4.0) (http://creativecommons.org/licenses/ by $/ 4.0$ )
\end{abstract}

\section{INTRODUCTION}

In 3 phase high voltage system, about $70-90 \%$ of the faults Are line to ground faults. During line to ground fault, the fault current rises to abnormally high levels in the faulty phase which stresses the generators and power transformer winding. Mechanical forces on the windings which will develop due to this fault current, are proportional to the square of the fault currents. This may cause crushing, bending, stretching of conductors and insulation degradation, which ultimately results in failure of generators and transformer.

The purpose of the reactor is to reduce the magnitude of ground fault currents. This is expected to increase transformer life expectancy by significantly reducing transformer short circuit forces. The higher ground impedance provided by the (NGR) also causes an increased voltage drop in the ground return path, raising the temporary overvoltage on the un faulted phases and deepening the voltage sag on the faulted phase during a ground fault. The reduction in ground fault current requires the modification of ground protective device coordination and setting.
Reactors for Neutral Grounding can be dry type or oil immersed, where dry type can be both iron cored and air cored. Air core reactors are oil free hence the maintenance, fire hazard risk, oil leakages and cost are less. Iron cored reactors are prone to magnetic saturation at high current levels, this limitation can be mitigated by the use of air cored reactors. Air core reactors show a linear characteristics of current and magnetic flux where as iron cored reactors show a linear relationship up to saturation knee point.

\section{Principle}

A. Neutral grounding reactor

In reactance grounding, when NGR is added between the neutral and the earth in the fault path, the magnitude of fault current which will reduce will depend on the impedance of the NGR. NGR adds to the zero sequence impedance of the system and not to the positive sequence impedance. The effect of impedance of NGR is large for faults near the substation compared with the faults occurring further away from the substation. Grounding is said to be effective if the ratio of zero sequence impedance to positive sequence impedance of the system is less than or equal to three. As increase in zero sequence impedance greater than this value can cause transient over voltages. Due to this, single line to 
ground fault current has to be restricted to maximum $60 \%$ of the three phase fault current.

NGR"s only provide protection against single line to ground faults. They are not useful during line to line fault. Line to ground faults if not cleared, it progresses to line to line fault if the fault side energy is high. Thus NGR indirectly reduces the number of line to line faults in the system.

$\mathrm{XNGR}=(\mathrm{VL} / \sqrt{3})[(1 / \mathrm{I} 1)-(1 / \mathrm{I} 0)]$

$\mathrm{XNGR}=$ Reactance of the neutral grounding reactor, $\Omega$

$\mathrm{VL}=$ System line to line voltage, $\mathrm{kV}$

I0 = Single line to ground fault current before introducing NGR in $\mathrm{kA}$.

I1 = Required single line to ground fault current after introducing NGR in kA.

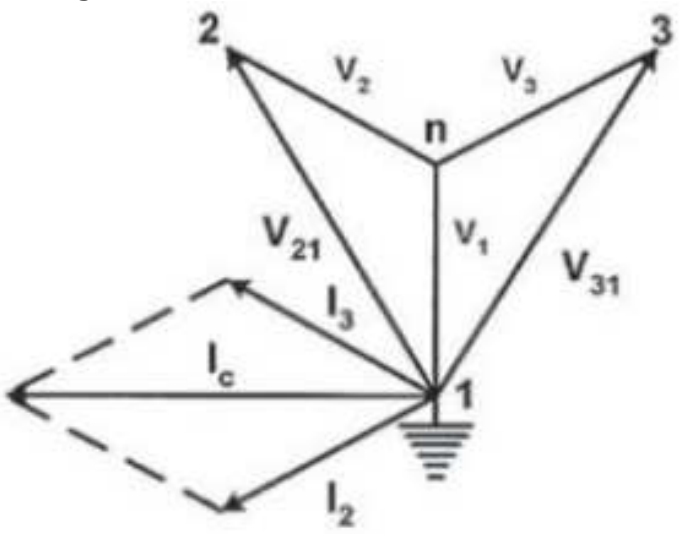

Fig. 1 Phasor diagram of single line to ground fault of ungrounded system

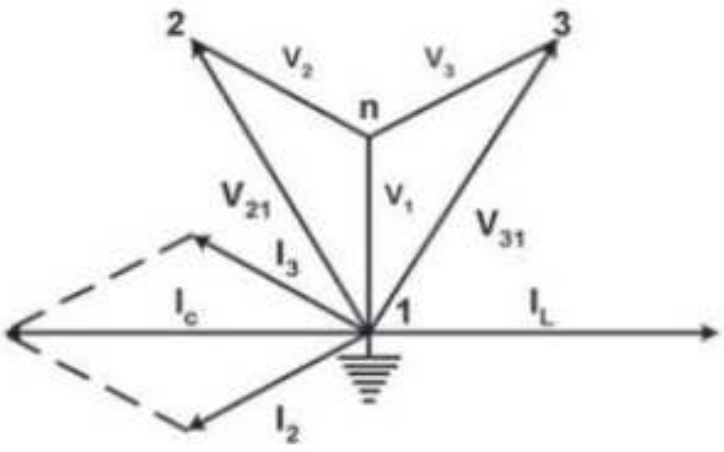

Fig.2 Phasor diagram of single line to ground fault of grounded system with NGR

\section{B. Neutral grounding reactor for transformer}

The fault current flows from transformer winding, through line and then to the ground. Addition of NGR between the transformer neutral bushing and the substation ground increases the total impedance of the return path for the fault currents. A NGR is an inductor intentionally inserted between the transformer's neutral and the system ground. The impedance of the NGR adds to the impedance of the grounding system, raising the total impedance that ground currents must flow through. Since the magnitude of a impedance is determined by dividing the system voltage by the rated current $(\mathrm{Z}=\mathrm{V} / \mathrm{I})$, the additional impedance reduces the magnitude of the fault current. Only ground faults are affected by a NGR.
The transformer specification for which the NGR is designed and the NGR specification are given in the table I and II.

TABLE I TRANSFORMER SPECIFICATION TRANSFORMER SPECIFICATION

\begin{tabular}{|c|c|c|}
\hline \multicolumn{2}{|c|}{ MVA RATING } & 1MVA \\
\hline \multirow{2}{*}{ VOLTAGE } & LV & $415 \mathrm{~V}$ \\
\cline { 2 - 3 } & $\mathrm{HV}$ & $11000 \mathrm{~V}$ \\
\hline \multirow{2}{*}{ CURRENT } & $\mathrm{LV}$ & $1391 \mathrm{~A}$ \\
\cline { 2 - 3 } & $\mathrm{HV}$ & $53 \mathrm{~A}$ \\
\hline TYPE OF COOLING & ONAN \\
\hline VECTOR GROUP & DYN11 \\
\hline \multicolumn{2}{|c|}{ FREQUENCY } & $50 \mathrm{~Hz}$ \\
\hline \multicolumn{2}{|c|}{ PHASE } & 3 \\
\hline \multicolumn{2}{|c|}{ OIL QUANTITY } & $750 \mathrm{LTR}$. \\
\hline
\end{tabular}

TABLE II REACTOR SPECIFICATION

\begin{tabular}{|l|l|}
\hline \multicolumn{2}{|c|}{ REACTOR } \\
\hline INDUCTANCE & $388 \mathrm{MH}$ \\
\hline REACTANCE & $122 \Omega$ \\
\hline
\end{tabular}

III. SIMULATION

A. Simulation Model

Simulation Model of the system under normal condition

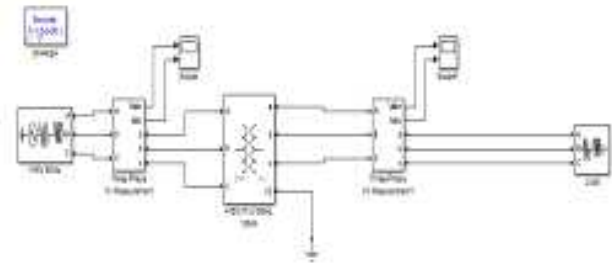

Fig. 3 Simulation model of System under pre-fault condition

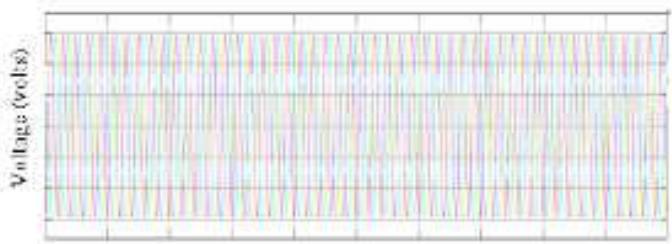

Time (sec) Fig. 4 Primary Voltage

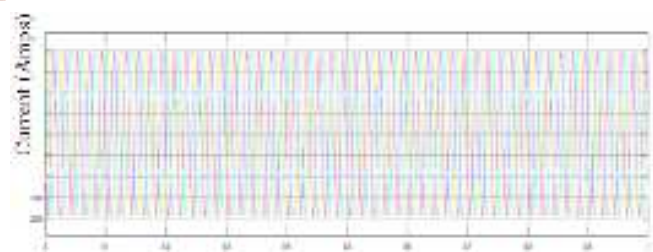

Time (sec) Fig. 5 Primary Current

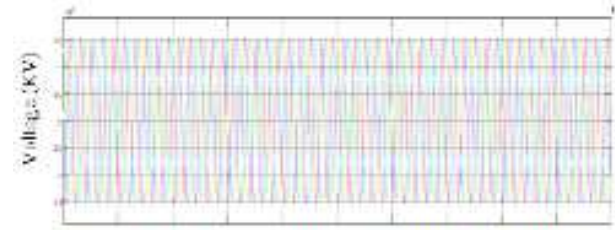

Time (sec) Fig. 6 Secondary Voltage

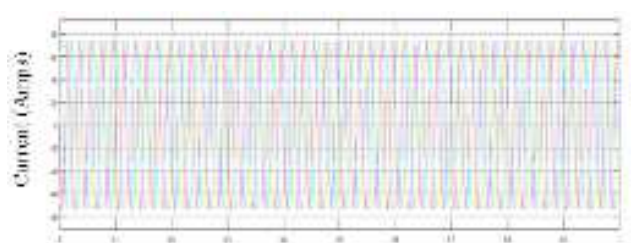

Time (sec) Fig. 7 Secondary Current 


\section{B. During Fault Condition}

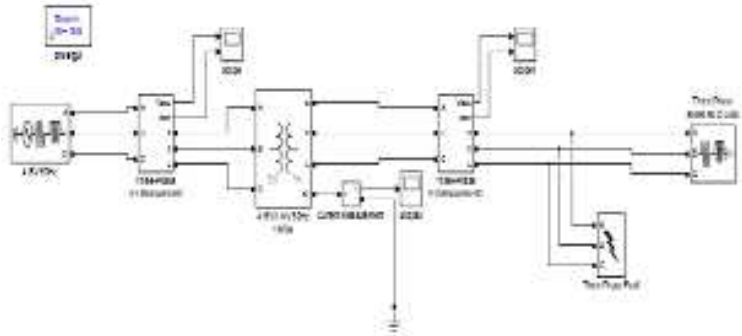

Fig. 8 Simulation model of System under fault condition
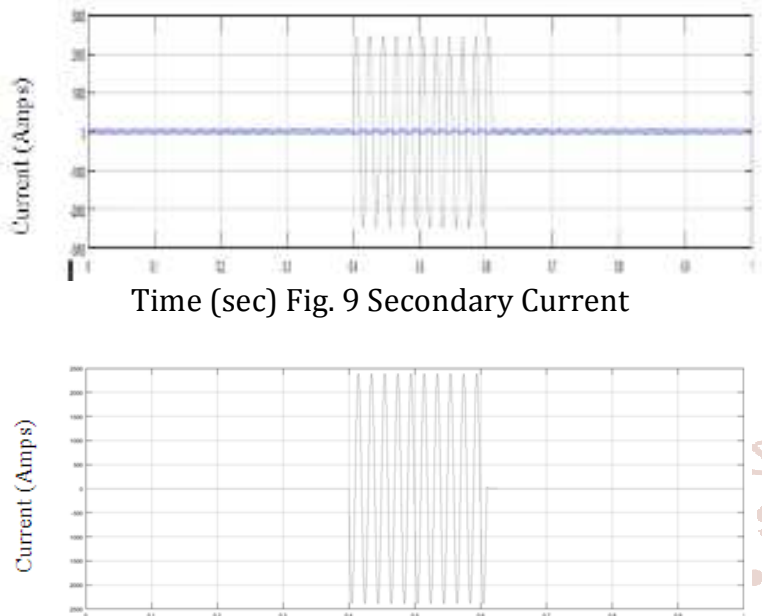

Time (sec) Fig. 10 Neutral Current

\section{During fault with NGR}

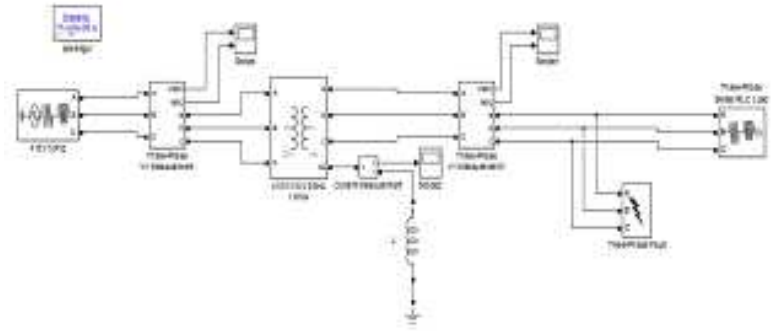

Fig. 11 Simulation model of System under fault condition with NGR
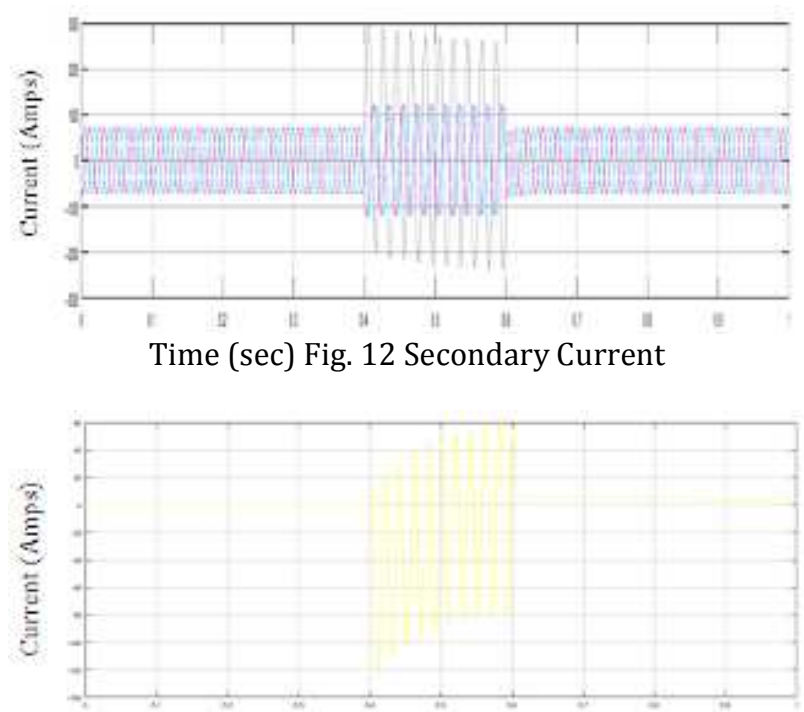

Time (sec) Fig. 13 Neutral Current
IV. Calculation

A. Primary Side Transformer Calculation

Vrms $=\frac{V \max }{\sqrt{2}}=583=412 \mathrm{~V}$

$\sqrt{2} \quad \sqrt{2}$

$\operatorname{Irms}=\frac{\operatorname{Imax}}{\sqrt{2}}=\frac{1951}{\sqrt{2}}=1379.56 \mathrm{~A}$

$\sqrt{2} \quad \frac{1951}{\sqrt{2}}$

B. Secondary Side Transformer Calculation

Vrms $=\underline{\text { Vmax }}=\underline{15400}=10889.44 \mathrm{~V}$

$\sqrt{2} \quad \sqrt{2}$

Irms $=\underline{\operatorname{Imax}}=\underline{73}=51.6 \mathrm{~A}$

$$
\sqrt{2} \quad \sqrt{2}
$$

\section{ADVANTAGES OF NGR}

1. Perfect mechanical strength to withstand high shortcircuit forces

2. Limited temperature rise enables longer lifetime

3. Special surface protection against UV and pollution Class IV areas

4. Maintenance-free design

5. Low noise levels

\section{CONCLUSION}

In high voltage system, Neutral grounding is more cost effective than resistance grounding because NGR has low resistance and hence does not dissipate a large amount of thermal energy.

Neutral Grounding Air core type reactor will provide cost effective and maintenance free solution as compared to oil filled reactors Hence NGR was designed and mounted at the industry location i.e. Paramount Conductors Ltd. For 1 MVA Testing Transformer.

\section{REFERENCES}

[1] IEEE Guide for Application of Transformer Connections in Three Phase Distribution Systems, IEEE STD C57. 105-1978(R2008).

[2] Patrick Sorrells and Alberto Benitez, "Power Transformer Neutral Grounding Reactor Application and Distribution Feeder Protection Issues at Center point Energy," IEEE 2005.

[3] Donald Selkirk and Mervin Savostianik. "The Danger of NGR Failure." IEEE Industry Applications, October 2010.

[4] Mohammad Reza Dadash Zadeh, Majid Sanaye-Pasand and Ali Kadivar "Investigation of Neutral Reactor Performance in Reducing Secondary Arc Current", IEEE Transactions On Power Delivery, vol.23, No. 4, October 2008.

[5] Anikesh D. Mathane, Dr H. A. Mangalvedekar, Shubhangi Patil and Mihir U. Kesarker. "Selection of Neutral Grounding Reactor for Line to Ground Fault." IJRET Vol. 4 Issue 05, May-2015, pg-1359-1362.

[6] "Handbook on Transformer", by ABB, $3^{\text {rd }}$ Edition. 